\title{
Bacterial entombment by intratubular mineralization following orthograde mineral trioxide aggregate obturation: a scanning electron microscopy study
}

\author{
Jun Sang Yoo ${ }^{1, *}$, Seok-Woo Chang ${ }^{2, *}$, So Ram $\mathrm{Oh}^{3}$, Hiran Perinpanayagam ${ }^{4}$, Sang-Min Lim ${ }^{5}$, Yeon-Jee Yoo ${ }^{3}$, \\ Yeo-Rok $\mathrm{Oh}^{1}$, Sang-Bin $\mathrm{Woo}^{1}$, Seung-Hyun $\mathrm{Han}^{6}$, Qiang $\mathrm{Zhu}^{7}$ and Kee-Yeon Kum ${ }^{3}$
}

The time domain entombment of bacteria by intratubular mineralization following orthograde canal obturation with mineral trioxide aggregate (MTA) was studied by scanning electron microscopy (SEM). Single-rooted human premolars $(n=60)$ were instrumented to an apical size \#50/0.06 using ProFile and treated as follows: Group $1(n=10)$ was filled with phosphate buffered saline (PBS); Group 2 $(n=10)$ was incubated with Enterococcus faecalis for 3 weeks, and then filled with PBS; Group 3 ( $n=20)$ was obturated orthograde with a paste of OrthoMTA (BioMTA, Seoul, Korea) and PBS; and Group $4(n=20)$ was incubated with $E$. faecalis for 3 weeks and then obturated with OrthoMTA-PBS paste. Following their treatments, the coronal openings were sealed with PBS-soaked cotton and intermediate restorative material (IRM), and the roots were then stored in PBS for 1, 2, 4, 8 or 16 weeks. After each incubation period, the roots were split and their dentin/MTA interfaces examined in both longitudinal and horizontal directions by SEM. There appeared to be an increase in intratubular mineralization over time in the OrthoMTA-filled roots (Groups 3 and 4). Furthermore, there was a gradual entombment of bacteria within the dentinal tubules in the $E$. faecalis inoculated MTA-filled roots (Group 4). Therefore, the orthograde obturation of root canals with OrthoMTA mixed with PBS may create a favorable environment for bacterial entombment by intratubular mineralization. International Journal of Oral Science (2014) 6, 227-232; doi:10.1038/ijos.2014.30; published 11 July 2014

Keywords: bacterial entombment; intratubular mineralization; orthograde canal obturation; scanning electron microscopy; tag-like structure

\section{INTRODUCTION}

The role of bacteria in initiating and perpetuating pulp and periapical disease is well established. ${ }^{1}$ Therefore, the purpose of endodontic treatment is to eliminate microorganisms from the root canal system, and to prevent recontamination by creating a fluid-tight seal between the canal and the obturating material. ${ }^{2}$ For this purpose, a material which can completely seal the infected root canal system would be ideal for clinical practice. However, previous studies showed that current root canal obturation materials such as gutta-percha and/or polymer-based materials cannot provide a bacteria-tight seal. ${ }^{3-6}$

Mineral trioxide aggregate (MTA) has been successfully used as a biomaterial in both surgical and nonsurgical endodontics. MTA has been shown to provide superior sealing ${ }^{7}$ and biomineralization ability, ${ }^{8}$ despite concerns about the macro- or microporous structure of the material caused by inadequate water-to-powder ratio, insufficient packing or water evaporation. ${ }^{9-11}$ Indeed, it has been reported that the porosity caused by dissolution of calcium hydroxide within MTA could be 'selfrepaired' by mineral precipitates such as calcium silicate hydrate gel that is formed by the hydration reaction of the material, ${ }^{12-13}$ and the tag-like structures formed at the MTA/dentin interface. ${ }^{14-15}$ These characteristic structures appear to be important in sealing dentinal tubules and biomineralization of the material. For biomineralization, the interaction of MTA and phosphate-buffered saline (PBS) triggers the initial precipitation of calcium-deficient carbonated apatites via an amorphous calcium phosphate phase, which further promotes the process. ${ }^{11,14,16-18}$ Furthermore, it has been reported that these carbonated apatites promote the formation of an interfacial layer with tag-like structures at the MTA/ dentin interface. ${ }^{11}$ Consequently, MTA-induced biomineralization may be enhanced if PBS is used as the mixing vehicle for hydration. However, there have not been any studies on the effectiveness of MTA-PBS paste as an obturation material, and little is known about the capacity for MTAinduced biomineralization to entomb bacteria in infected root canals.

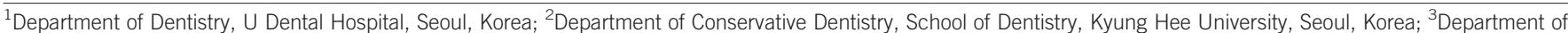

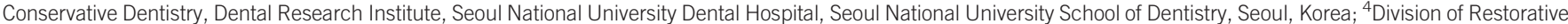

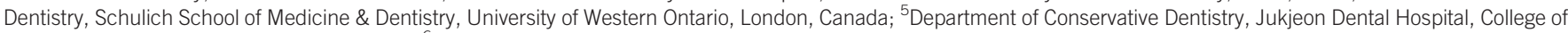

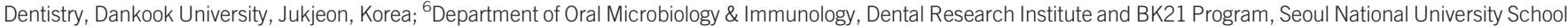

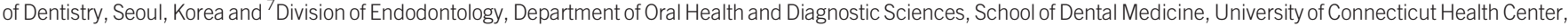
Farmington, USA

*These authors contributed equally to this work.

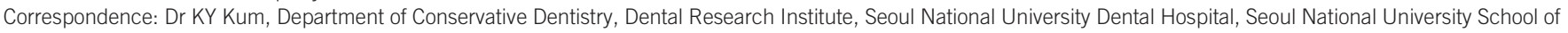
Dentistry, 25-9 Jongro-Gu Yungun-Dong, Seoul 110-768, Korea

E-mail: kum6139@snu.ac.kr

Accepted 2 April 2014 
OrthoMTA (BioMTA, Seoul, Korea) is a newly developed MTA cement for orthograde root canal obturation, that is mainly composed of tricalcium silicate and contains less heavy metal than the original ProRoot MTA (Dentsply, Tulsa, OK, USA). ${ }^{19}$ Therefore, the aim of this study was to examine the effects of MTA-induced biomineralization with regard to bacterial entombment in dentinal tubules, by using OrthoMTA-PBS paste as the root canal obturation material. The null hypothesis was that the OrthoMTA-PBS obturation can effectively entomb bacteria by intratubular mineralization in Enterococcus faecalis-infected root canals.

\section{MATERIALS AND METHODS}

Selection and preparation of teeth

This study was carried out under the approval of the Institutional Review Board of Seoul National University Dental Hospital, Seoul, Korea. Sixty human single-rooted premolars with fully formed apices that were without root cracks or defects when viewed under a microscope (OPMI Pico, Carl Zeiss, Germany) were collected from patients undergoing extractions for orthodontic reasons in the Department of Oral and Maxillofacial Surgery. All of the teeth were decoronated with a Minitom saw (Struers, Rodovre, Denmark), and apical patency was obtained with a size \#10 stainless steel K-file (Dentsply, Tulsa, OK, USA). The working length was determined to be $1 \mathrm{~mm}$ short of the apical foramen when visually inspected with a size \#10 stainless steel K-file (Dentsply, Tulsa, OK, USA). The coronal third of the canals were flared with Gates Glidden burs \#2-4 (Komet, Rock Hill, SC, USA). The canals were then instrumented to an apical size \#50/.06 with a crown-down technique using ProFile 0.04 and $0.06 \mathrm{Ni}-\mathrm{Ti}$ rotary instruments (Dentsply Maillefer, Ballaigues, Switzerland), and copiously irrigated with $5.25 \%$ sodium hypochlorite and $17 \%$ ethylenediaminetetraacetic acid (EDTA) between instruments. The smear layer was removed from the canal walls by immersing the specimens for 5 min each in $17 \%$ EDTA (pH 7.2) followed by $5.25 \%$ sodium hypochlorite within an ultrasonic bath (Elmasonic 1 Ultrasonic Cleaner; Camlab, Cambridge, UK). They were then rinsed copiously with distilled water and dried with paper points. Finally they were autoclaved at $121{ }^{\circ} \mathrm{C}$ for $15 \mathrm{~min}$ to ensure that there was no bacterial contamination, and then incubated in brain heart infusion (BHI) broth at $37{ }^{\circ} \mathrm{C}$ for $24 \mathrm{~h}$. The roots were stored at $37{ }^{\circ} \mathrm{C}$ in $100 \%$ humidity until use.

\section{Bacterial inoculation and root canal obturation}

The schematic diagram provides an overview of the experimental procedures (Figure 1). Roots were randomly assigned to four groups that determined whether or not they would receive an inoculation and/or an MTA obturation. Group 1: 10 sterile roots were filled with PBS; Group 2: 10 inoculated roots were filled with PBS; Group 3: 20 sterile roots were orthograde filled with OrthoMTA-PBS; Group 4: 20 inoculated roots were orthograde filled with OrthoMTA-PBS paste. Each group was further subdivided into five subgroups for the observation periods $1,2,4,8$ and 16 weeks.

Enterococcus faecalis was grown overnight in $\mathrm{BHI}$ broth, adjusted to a turbidity of 0.5 on the McFarland scale $\left(1.5 \times 10^{8} \mathrm{CFU} \cdot \mathrm{mL}^{-1}\right)$ and

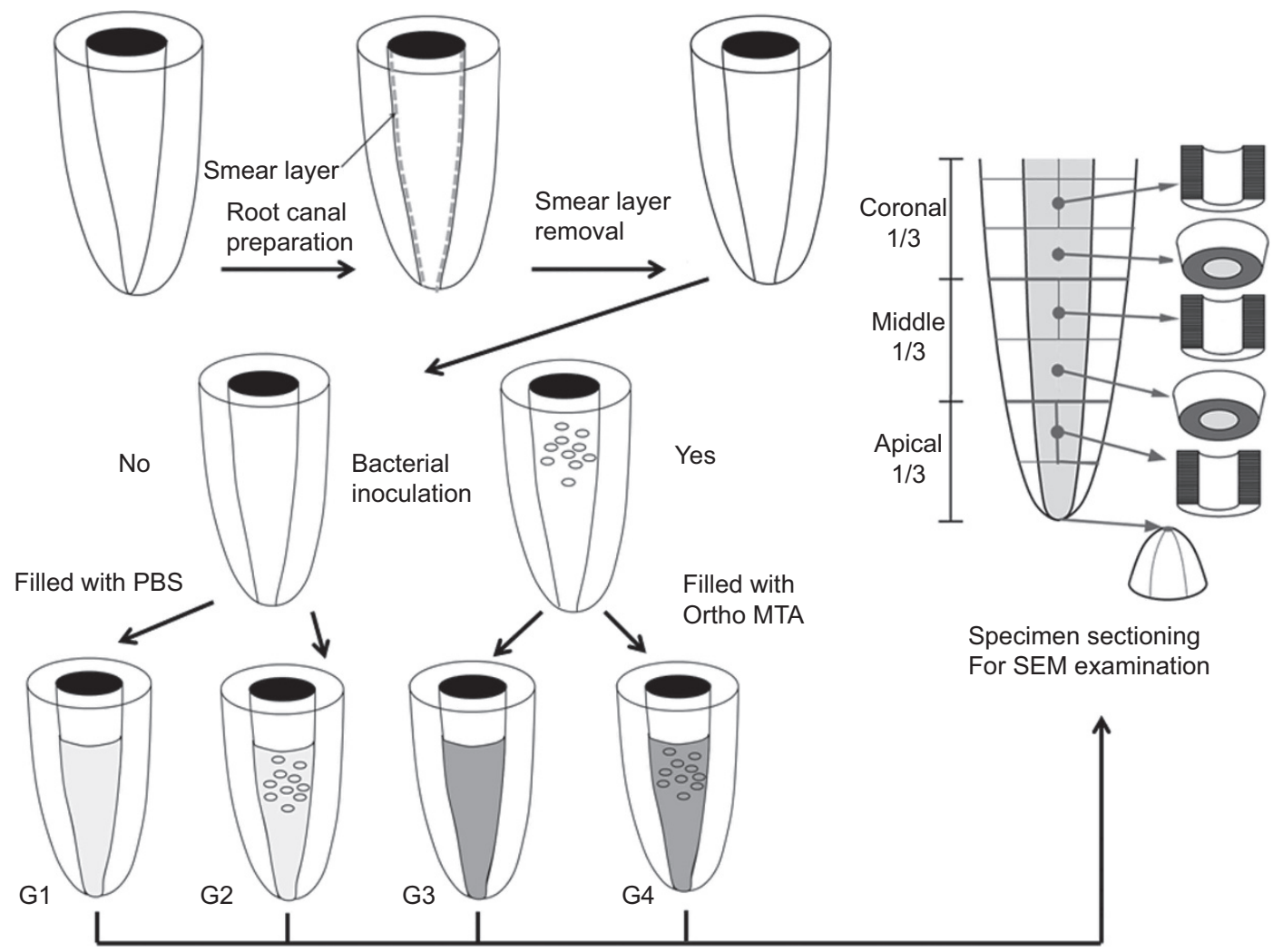

Figure 1 Schematic drawing of experimental flow chart used in this study. G1 (Group 1), no bacterial inoculation and filled with PBS; G2 (Group 2), bacterial inoculation and filled with PBS; G3 (Group 3), no bacterial inoculation and filled with OrthoMTA-PBS paste; G4 (Group 4), bacterial inoculation and filled with OrthoMTA-PBS paste into root canal. Each specimen was sectioned in a way that allows cross-sectional, longitudinal and apical examination by SEM. MTA, mineral trioxide aggregate; PBS, phosphate-buffered saline; SEM, scanning electron microscopy. 
inoculated into all root canal lumens in Groups 2 and 4 . All of the roots were then placed into conical tubes containing fresh BHI $(20 \mathrm{~mL})$ that was replaced every second day, and incubated for 3 weeks at $37{ }^{\circ} \mathrm{C}$ in a humidified incubator with 5\% $\mathrm{CO}_{2}$ (BBD $6220 \mathrm{CO}_{2}$ incubator; Thermo Fisher Scientific, Waltham, MA, USA). The purity of the cultures was confirmed by gram staining, catalase production and colony morphology on BHI blood agar.

Following this incubation, the root canals were copiously irrigated with saline and dried with sterile paper points. Then, all of the canals in Groups 3 and 4 were filled to their working length with OrthoMTA cement (BioMTA, Seoul, Korea). The OrthoMTA powder was mixed with PBS (liquid/powder=0.3) with a sterile plastic stick, and an MTA carrier (BioMTA, Seoul, Korea) was used to insert MTA incrementally into each canal. An OrthoMTA Ni-Ti compactor and hand pluggers (BioMTA, Seoul, Korea) were used alternatively to condense the MTA increments and prevent voids. The OrthoMTA compactor was applied with a continuous, slight pecking movement using a reduction handpiece $(128: 1 ; \mathrm{W} \& \mathrm{H}$ Dentalwerk Burmoos GmbH, Burmoos, Austria) and electric motor (TCM 3000; Nouvag AG, Goldach, Switzerland) at $60 \mathrm{r} \cdot \mathrm{min}^{-1}$. All of the obturations were performed by a single endodontist, and radiographs were taken to ensure that the canals were adequately filled and without voids. Similarly, the canals in Groups 1 and 2 were filled with PBS. Then, the cervical $3 \mathrm{~mm}$ of all root canals were packed with PBS-soaked sterile cotton and sealed with intermediate restorative material (IRM; Dentsply Caulk, Milford, DE, USA). Finally, the roots were stored in sterile plastic vials containing $20 \mathrm{~mL}$ of PBS that was replaced weekly for $1,2,4,8$ or 16 weeks at $37{ }^{\circ} \mathrm{C}$.

\section{Scanning electron microscopy analysis}

At the end of each incubation period (1, 2, 4, 8 and 16 weeks), each root was aseptically transferred from its vial to a Teflon beaker that was covered with sterile foil (Nalgene Labware, Rochester, NY, USA). The roots were then split in half by creating two parallel longitudinal grooves on their outer surfaces with slow-speed carborundum disks (Henan Meijiasheng Trading, Zhengzhou, China), and using sterile long-handled end cutting pliers (Channellock, Meadville, PA, USA). To prevent contamination, the beaker was kept covered throughout this process. Each sample was prefixed with a PBS solution of $2.5 \%$ glutaraldehyde and $2 \%$ paraformaldehyde $(\mathrm{pH} 7.2)$ at $4{ }^{\circ} \mathrm{C}$ overnight and washed 3 times with PBS solution ( $\mathrm{pH} 7.2)$. For post fixation, each sample was treated with $1 \%$ osmium tetroxide for $1.5 \mathrm{~h}$ then washed three times with distilled water and dehydrated in graded ethyl alcohol (70\%-80\%-90\%-95\%-100\% each for $15 \mathrm{~min}$ and $100 \%$ for $15 \mathrm{~min}$ ). The samples were dried with hexamethyldisilazane in air overnight before coating with ionbeam sputtering. The split roots were then mounted on aluminum stubs, sputter coated with a $30 \mathrm{~nm}$ layer of gold and examined both longitudinally and cross-sectionally along the MTA-dentin interfaces of the canals by Scanning electron microscopy (SEM, Model S4700; Hitachi, Tokyo, Japan). The voltage was set to $15 \mathrm{kV}$, the type of signal used was secondary electrons, the working distance was $12 \mathrm{~mm}$ and the scan speed was 16 frames per $20 \mathrm{~s}$. The central areas of each sample were photographed.

\section{RESULTS}

There were no mineral precipitates in dentinal tubules of all the nonMTA filled root in Groups 1 and 2 until 16-weeks' observation period (Figure $2 \mathrm{a}$ and $2 \mathrm{~b}$ ), whereas the formation of uniform tag-like structures was generally found over entire surface at coronal (Figure $2 \mathrm{c}$ and 2d), middle (Figure 2e and 2f) and apical (Figure $2 \mathrm{~g}$ and $2 \mathrm{~h}$ ) parts of all the MTA-filled root in Groups 3 and 4.

In Group 3, the formation of tiny leaflet-like crystalline structures indicated a biomineralization process on the dentinal tubular surface in a 1-week specimen (white arrows, Figure $3 \mathrm{a}$ and $3 \mathrm{~b}$ ). In a 2-week sample, it was observed that the tag-like structures obstructed the entrance of dentinal tubule and the crystalline structures were formed inside the dentinal tubules (Figure 3c). The 4-week sample showed
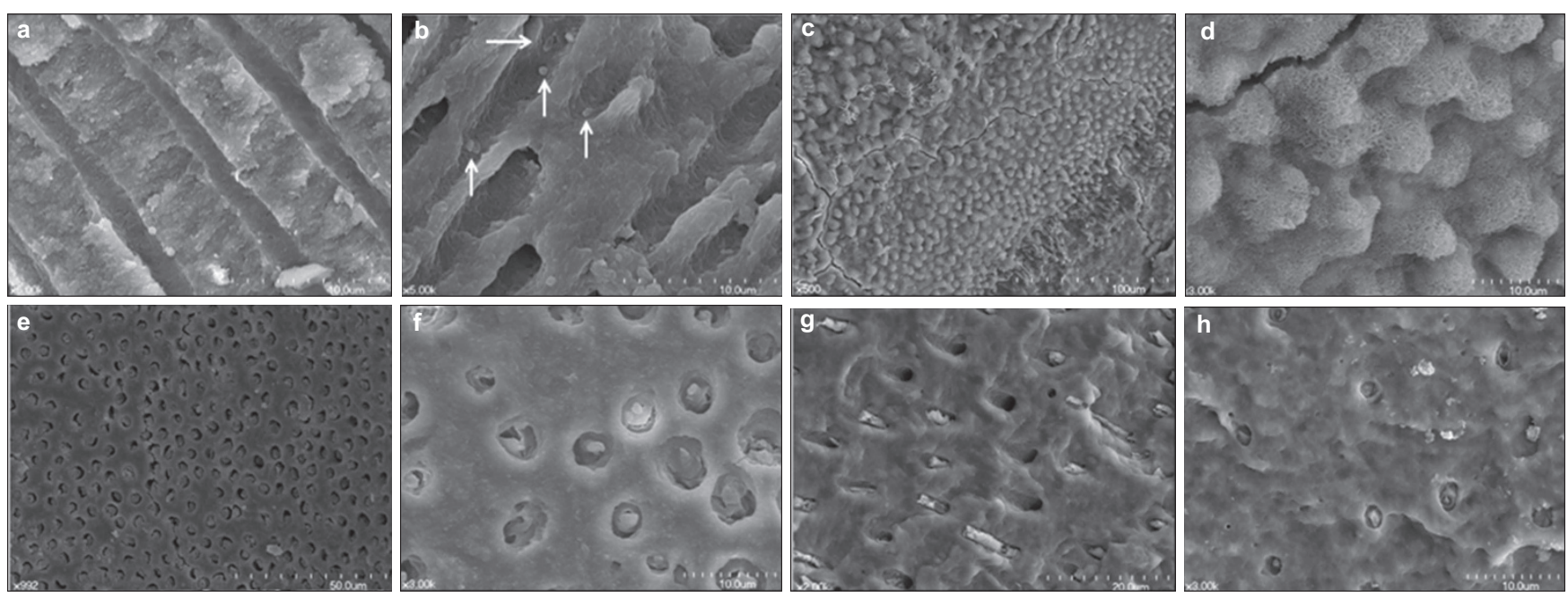

Figure 2 All the samples of MTA-filled group showed uniform formation of tag like structure that obliterates the dentinal tubules. (a) SEM view of a representative specimen showing no mineral precipitation at 16-weeks specimen in Group 1 ( $\times 5000)$. (b) SEM view of a representative specimen showing a few E. faecalis scattered in dentinal tubules at 16 weeks specimen in Group 2 (white arrows, $\times 5000$ ). (c) The orifices of coronal dentinal tubules were obliterated by the short tag-like precipitates $(\times 500)$. (d) These short tags matched exactly the entrances of all dentinal tubule orifices $(\times 3000)$. (e) The middle dentinal tubules were obliterated ( $\times 500)$. (f) The magnified view of obliterated middle dentinal tubules $(\times 3000)$. (g) In this oblique cutting image, the apical dentinal tubules were obliterated by long tags ( $\times 2000$ ). (h) The numbers and sizes of apical dentinal tubules were small. All dentinal tubules were also effectively filled with the hydration product of MTA. MTA, mineral trioxide aggregate; SEM, scanning electron microscopy. 

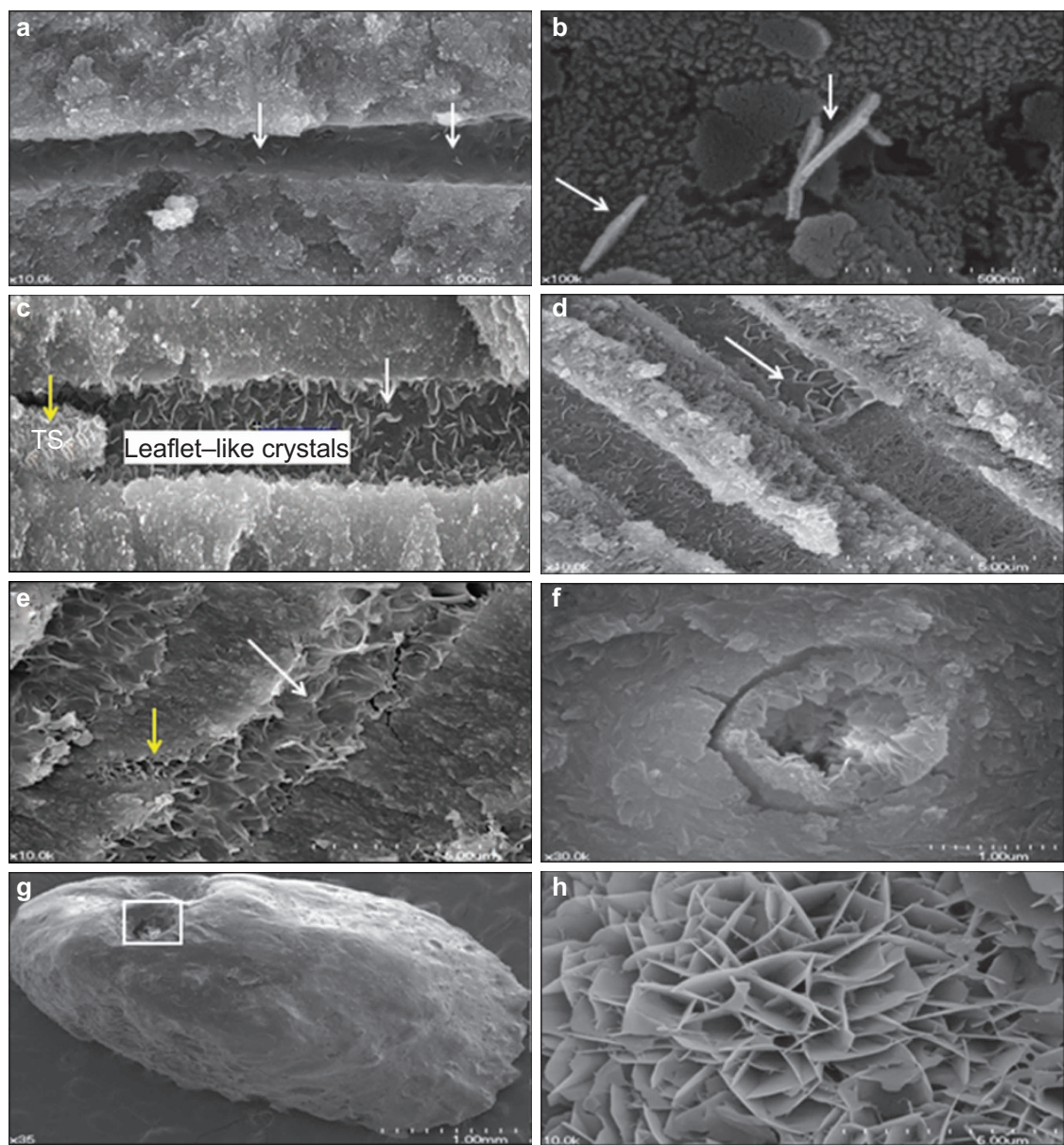

Figure 3 SEM views of representative specimens in Group 3. (a) SEM showing a rare, scattered distribution of leaflet-like crystals in a 1-week specimen of Group 3 (white arrows, $\times 10000$ ). (b) In 1-week specimen of Group 3, a magnified view of tiny leaflet-like crystals (white arrows, $\times 100000$ ) indicated epitaxial growth on the dentinal tubular surface. (c) A 2-week specimen of Group 3 showing the formation of leaflet-like crystals (white arrows) and tag-like structure (TS, yellow arrow) in a dentinal tubule in Group 3 ( $\times 30000$ ). (d) A 4-week specimen of Group 3 showing that crystal formation was initiated simultaneously on almost whole surface of the dentinal tubules $(\times 10000)$. The white arrow shows that the leaflet-like crystalline structures were increased and packed densely in the dentinal tubules. (e) An 8 -week control specimen of Group 3 showing almost complete obstruction of dentinal tubules by the newly formed crystalline structures in Group 3 (white arrow). The yellow arrow indicates that even the intercanalicular space could be filled completely with newly formed crystalline structures $(\times 10000)$. (f) A cross-sectional scanning electron microscopic view of a 16-week specimen in Group $3(\times 30000)$. The lumen of dentinal tubule was almost completely obstructed with newly formed crystalline structures. (g) A SEM view showing that apical foramen was obturated with newly formed crystalline structures, in a 4-week sample of Group 3 ( $\times 35$ ). (h) A magnified view of the square area in $\mathbf{g}$. The newly formed crystalline structures were observed at the surface of set MTA which obturated the apical foramen, in a 4-week sample of Group 3 (×10 000). SEM, scanning electron microscopy.

crystalline structures forming simultaneously on the entire surface of the dentinal tubules observed (white arrow, Figure 3d). After 8 weeks, the specimen showed obstruction of the dentinal tubules by newly formed crystalline structures (white arrow, Figure 3e). A cross-sectional SEM view of a 16-week specimen showed almost complete obstruction of the dentinal tubule lumens by growth of newly formed crystalline structures (Figure 3f). Not only dentinal tubules but also the apical foramen was shown to be obliterated with newly formed crystalline apatite structures in 4-week specimens in Group 3 (Figure $3 \mathrm{~g}$ and $3 \mathrm{~h}$ ).

In Group 4, the dentinal tubules harbored E. faecalis, and the distinctive crystalline structures had not yet formed in 1-week sample (white arrow, Figure 4a). In the 2-week sample, the needle-like crystalline structures grew along the entire wall of the dentinal tubules (white arrows, Figure $4 \mathrm{~b}$ ), indicating that bacterial entombment had begun in this period. A 4-week specimen showed E. faecalis entombment resulting from narrowing of the infected dentinal tubules by the formation of leaflet-like crystals (Figure 4c). The yellow arrow reveals a crumbled appearance of E. faecalis. A magnified view of the yellow rectangular area in Figure 4c showed that each $E$. faecalis bacterium is being entombed by a growing crystalline structure (Figure 4c). An 8-week sample showed the almost complete obstruction of the lumen of the infected dentinal tubule by leaflet-like crystalline structures and entombed bacteria (white arrow). The yellow arrows showed the sites that E. faecalis had been entombed and detached in the process of preparing the samples for SEM (Figure 4e). The 16-week sample showed that newly formed crystalline structures appeared in tiny needle-like structures (yellow arrow) or as an agglomerate of leaflet-like structures (white arrow) in almost the whole dentinal tubule (Figure 4f). The crystalline structures were formed in the apical foramen area of a 12-week sample (Figure $4 \mathrm{~g}$ ), which showed a small amount of needle-like crystals among the plate-like ones (Figure 4h). 

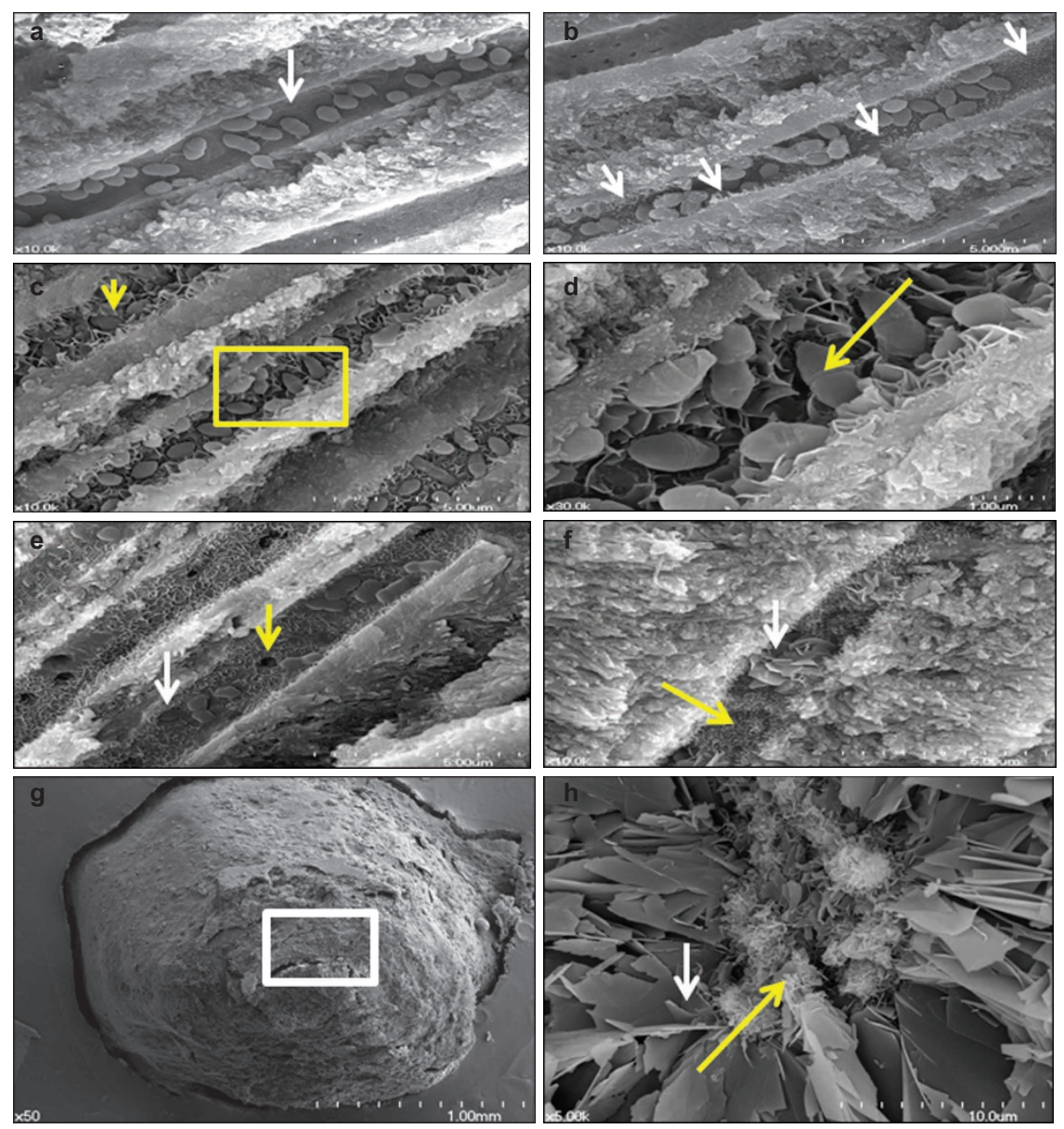

Figure 4 SEM views of representative specimens in Group 4. (a) A 1-week specimen showing a dentinal tubule occupied by E. faecalis (white arrow) in Group 4; the formation of the distinctive crystals was not yet observed in the dentinal tubule $(\times 10000)$. (b) A 2-week specimen showing the initial stage of $E$. faecalis entombment by the gradual formation of needle-like crystals along the entire wall of the infected dentinal tubules (white arrows, $\times 10000$ ). (c) A 4-week specimen showing $E$. faecalis entombment resulting from narrowing of the infected dentinal tubules by the formation of leaflet-like crystals $(\times 10000)$. The yellow arrow reveals a crumbled appearance of $E$. faecalis. (d) A magnified SEM view of yellow rectangular area in c. E.faecalis bacterium is being entombed by growing crystalline structure ( $\times 30000)$. Yellow arrow shows the damaged cell membrane of $E$. faecalis. (e) An 8-week specimen showing obstruction of the infected dentinal tubules and entombed bacteria (white arrows) by leaflet-like crystals. The yellow arrows show that $E$. faecalis had been entombed and lost from the dentinal tubules in the process of preparing the sample for SEM $(\times 10000)$. (f) A 16-week specimen showing complete blockage of the dentinal tubules by an aggregation of leaflet-like (white arrow) and needle-like (yellow arrow) crystals ( $\times 10000)$. (g) A 12-week specimen showing OrthoMTA obturated at apical foramen area ( $\times 50)$. (h) A magnified SEM view of white rectangular area in $\mathbf{g}$ showed small amount of needle-like crystals (yellow arrow) among the plate-like ones (white arrow) ( $\times 5000)$. MTA, mineral trioxide aggregate; SEM, scanning electron microscopy.

\section{DISCUSSION}

This is the first study to have shown bacterial entombment by intratubular mineralization over time following orthograde obturation with MTA. The entombment of intracanal bacteria was suggested by Sundqvist and Figdor ${ }^{20}$ to be one of the main objectives of root canal obturation. However, the entombment of bacteria within the root canal space has not been achieved by with either gutta percha or Resilon obturation materials. Gutta-percha used with sealers fail to seal the dentinal wall. ${ }^{4}$ Although the resin-based sealers in Resilon could effectively penetrate the dentinal tubules in moist dentin, they are still susceptible to the effects of matrix metalloproteinase in the dentin matrix. ${ }^{21-22}$ In contrast, MTA has been shown to resist leakage at a higher rate when placed in a moist environment such as the root canal system. ${ }^{23}$

Furthermore, recent studies have suggested that MTA-induced mineralization could be enhanced by the use of PBS. It was reported that the addition of phosphate to Portland cement that has a similar composition to MTA, accelerated the hydration reaction which improved the flexural strength and reduced the solubility of the set material. $^{24}$ Calcium and phosphate ions in PBS could precipitate amorphous calcium phosphate, ${ }^{25}$ which is a precursor of hydroxyapatite, and thereby promote carbonated apatite deposition and strengthen the MTA/dentin interface. ${ }^{16}$ Indeed, Martin et al. ${ }^{26}$ reported that immersion in PBS improved the marginal seal of MTA apical plugs. However, until now, there have not been any reports on the use of PBS as the mixing vehicle for MTA, and on its capacity to stimulate intratubular mineralization.

In every OrthoMTA-PBS paste-filled specimens, short tag-like structures obliterated the entrance of the dentinal tubules and long tag-like precipitates filling the dentinal tubule lumens were routinely observed. These characteristic features might decrease the nutritional supply to the intratubular bacteria, and their further growth into dentinal tubule might reduce the available space for bacterial survival and growth. The phosphorus required in intratubular crystalline growth process seems to have been supplemented from the dentinal fluid, ${ }^{27}$ as was reported by by Camilleri et al. ${ }^{28}$ The depletion of intratubular phosphorus might result in the inhibition of E. faecalis because 
the phosphorus ion is essential to the survival of E. faecalis. ${ }^{29}$ This bacterial entombing mechanism under moisture condition is a unique feature of MTA not previously reported in any of the other root canal filling materials. Considering the superior sealing ability ${ }^{30}$ and physiochemical and bioactive properties ${ }^{31-32}$ of the material as well, MTA appears to be a potential benefit as a root canal obturation biomaterial.

The chemical profile of the crystalline precipitates formed in this study was not fully confirmed yet. The crystalline structures observed in OrthoMTA-PBS filled roots might be carbonated apatites, resulting from biomineralization of hydrated MTA. ${ }^{14,33-34}$ A recent study ${ }^{35}$ speculated that intratubular crystalline precipitation induced by MTA is partly related to the transformation of metastable amorphous calcium phosphate phase into an apatite phase. Moreover, the platelike crystals and needle-like crystals observed at the apical foramen (Figure $4 \mathrm{~h}$ ), as reported in the study of Teng et al., ${ }^{36}$ might possibly are octacalcium phosphates and hydroxyapatites, respectively. Further studies to investigate chemical profiles of these structures are needed.

Although its intratubular biomineralization ability, MTA has some drawbacks such as irretrievability, tooth discoloration, and slow setting time as a canal obturation material. ${ }^{32}$ Also, there are concerns regarding the possibility of bacterial ingress by the formation of voids or porosities within MTA and at the MTA/dentin interface after obturation ${ }^{11}$ or hydration. ${ }^{9-10}$ Therefore, orthograde MTA obturation should be carefully performed to minimize the possible formation of voids/porosities and limited in selected clinical cases until its longterm benefits and prognosis is further confirmed.

\section{CONCLUSION}

Under the limitation of the present study, orthograde canal obturation with OrthoMTA-PBS paste could induce amorphous tag-like structure formation and intratubular crystalline growth over time which effectively entombs the intratubular bacteria. The present study suggests the potential antibacterial effect of orthograde obturation with OrthoMTA-PBS paste in infected root canals.

\section{ACKNOWLEDGEMENTS}

The authors deny any conflicts of interest related to this study. The authors give special thanks to J W Kim for his expertise and valuable guidance regarding the SEM observation. This research was supported by Basic Science Research Program through the National Research Foundation of Korea (NRF) funded by the Ministry of Education, Science and Technology (2009-0086835: Dr K Y Kum) and the Ministry of Science, ICT and Future Planning (2011-0014231: Dr S W Chang). This study was supported by a grant from the Kyung Hee University in 2013 (KHU-20131045).

1 Kakehashi S, Stanley HR, Fitzgerald RJ. The effects of surgical exposures of dental pulps in germ-free and conventional laboratory rats. Oral Surg Oral Med Oral Pathol 1965; 20: 340-349.

2 Siqueira JF Jr. Strategies to treat infected root canals. J Calif Dent Assoc 2001; 29(12): 825-837.

3 Brosco VH, Bernardineli N, Torres SA et al. Bacterial leakage in obturated root canals-part 2: a comparative histologic and microbiologic analyses. Oral Surg Oral Med Oral Pathol Oral Radiol Endod 2010; 109(5): 788-794.

4 Shashidhar C, Shivanna V, Shivamurthy G et al. The comparison of microbial leakage in roots filled with resilon and gutta-percha: an in vitro study. J Conserv Dent 2011; 14(1): 21-27.

5 Punia SK, Nadig P, Punia V. An in vitro assessment of apical microleakage in root canals obturated with gutta-flow, resilon, thermafil and lateral condensation: a stereomicroscopic study. J Conserv Dent 2011; 14(2): 173-177.

6 Santos J, Tjäderhane L, Ferraz $\mathrm{C}$ et al. Long-term sealing ability of resin-based root canal fillings. Int Endod J 2010; 43(6): 455-460.

7 Nair U, Ghattas S, Saber M et al. A comparative evaluation of the sealing ability of 2 root-end filling materials: an in vitro leakage study using Enterococcus faecalis. Oral Surg Oral Med Oral Pathol Oral Radiol Endod 2011; 112(2): e74-e77.
8 Reyes-Carmona JF, Felippe MS, Felippe WT. Biomineralization ability and interaction of mineral trioxide aggregate and white portland cement with dentin in a phosphatecontaining fluid. J Endod 2009; 35(5): 731-736.

9 Fridland M, Rosado R. Mineral trioxide aggregate (MTA) solubility and porosity with different water-to-powder ratios. J Endod 2003; 29(12): 814-817.

10 Saghiri MA, Asgar K, Lotfi M et al. Application of mercury intrusion porosimetry for studying the porosity of mineral trioxide aggregate at two different $\mathrm{pH}$. Acta Odontol Scand 2012; 70(1): 78-82.

11 El-Ma'aita AM, Qualtrough AJ, Watts DC. A micro-computed tomography evaluation of mineral trioxide aggregate root canal fillings. J Endod 2012; 38(5): 670-672.

12 Camilleri J. Characterization of hydration products of mineral trioxide aggregate. Int Endod J 2008; 41(5): 408-417.

13 Okiji T, Yoshiba K. Reparative dentinogenesis induced by mineral trioxide aggregate: a review from the biological and physicochemical points of view. Int J Dent 2009; 2009: 464280.

14 Tay FR, Pashley DH, Rueggeberg FA et al. Calcium phosphate phase transformation produced by the interaction of the Portland cement component of white mineral trioxide aggregate with a phosphate-containing fluid. J Endod 2007; 33(11): 1347-1351.

15 Dreger LA, Felippe WT, Reyes-Carmona JF et al. Mineral trioxide aggregate and Portland cement promote biomineralization in vivo. J Endod 2012; 38(3): 324-329.

16 Reyes-Carmona JF, Felippe MS, Felippe WT. A phosphate-buffered saline intracana dressing improves the biomineralization ability of mineral trioxide aggregate apical plugs. J Endod 2010; 36(10): 1648-1652.

17 Han L, Okiji T, Okawa S. Morphological and chemical analysis of different precipitates on mineral trioxide aggregate immersed in different fluids. Dent Mater J 2010; 29(5): 512-517.

18 Reyes-Carmona JF, Felippe MS, Felippe WT. The biomineralization ability of mineral trioxide aggregate and Portland cement on dentin enhances the push-out strength. $J$ Endod 2010; 36(2): 286-291.

19 Chang SW, Baek SH, Yang HC et al. Heavy metal analysis of ortho MTA and ProRoot MTA. J Endod 2011; 37(12): 1673-1676.

20 Sundqvist G, Figdor D. Endodontic treatment of apical periodontitis. In: Ørstavik D, Pitt Ford TR, ed. Essential endodontiology. Oxford: Blackwell, 1998: 242-277.

21 Tay FR, Pashley DH, Yiu CK et al. Susceptibility of a polycaprolactone-based root canal filling material to degradation. II. Gravimetric evaluation of enzymatic hydrolysis. J Endod 2005; 31(10): 737-741.

22 Zmener $\mathrm{O}$, Pameijer $\mathrm{CH}$, Serrano SA et al. Significance of moist root canal dentin with the use of methacrylate-based endodontic sealers: an in vitro coronal dye leakage study. J Endod 2008; 34(1): 76-79.

23 Chogle S, Mickel AK, Chan DM et al. Intracanal assessment of mineral trioxide aggregate setting and sealing properties. Gen Dent 2007; 55(4): 306-311.

24 Ma W, Brown P. Effect of phosphate additions on the hydration of Portland cement Adv Cem Res 1994; 21(6):1-12.

25 Dorozhkin SV. Amorphous calcium (ortho)phosphates. Acta Biomater 2010; 6(12): 4457-4475.

26 Martin RL, Monticelli F, Brackett WW et al. Sealing properties of mineral trioxide aggregate orthograde apical plugs and root fillings in an in vitro apexification model. J Endod 2007; 33(3): 272-275.

27 Weng J, Liu Q, Wolke JG et al. Formation and characteristics of the apatite layer on plasma-sprayed hydroxyapatite coatings in simulated body fluid. Biomaterials 1997 18(15): 1027-1035.

28 Camilleri J, Cutajar A, Mallia B. Hydration characteristics of zirconium oxide replaced Portland cement for use as a root-end filling material. Dent Mater 2011; 27(8): 845854.

29 Figdor D, Davies JK, Sundqvist G. Starvation survival, growth and recovery of Enterococcus faecalis in human serum. Oral Microbiol Immunol 2003; 18(4): 234-239.

30 Torabinejad M, Parirokh M. Mineral trioxide aggregate: a comprehensive literature review_part II: leakage and biocompatibility investigations. J Endod 2010; 36(2): 190-202.

31 Sarkar NK, Caicedo R, Ritwik P et al. Physicochemical basis of the biologic properties of mineral trioxide aggregate. J Endod 2005; 31(2): 97-100.

32 Bogen G, Kuttler S. Mineral trioxide aggregate obturation: a review and case series. $J$ Endod 2009; 35(6): 777-790.

33 Gandolfi MG, Taddei P, Tinti A et al. Kinetics of apatite formation on a calcium-silicate cement for root-end filling during ageing in physiological-like phosphate solutions. Clin Oral Investig 2010; 14(6): 659-668.

34 Eanes ED. Amorphous calcium phosphate. Monogr Oral Sci 2001; 18: 130-147.

35 Han L, Okiji T. Bioactivity evaluation of three calcium silicate-based endodontic materials. Int Endod J 2013; 46(9): 808-814.

36 Teng S, Shi J, Chen L. Formation of calcium phosphates in gelatin with a novel diffusion system. Colloids Surf B Biointerfaces 2006; 49(1): 87-92.

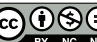

This work is licensed under a Creative Commons AttributionNonCommercial-NoDerivs 3.0 Unported License. The images or other third party material in this article are included in the article's Creative Commons license, unless indicated otherwise in the credit line; if the material is not included under the Creative Commons license, users will need to obtain permission from the license holder to reproduce the material. To view a copy of this license, visit http://creativecommons.org/licenses/ by-nc-nd/3.0/ 